\title{
INVESTIGACIÓN/RESEARCH
}

\section{EVOLUCIÓN DE LOS RASGOS CULTURALES DEL FORMATO TELEVISIVO "OPERACIÓN TRIUNFO" EN ESPAÑA DESDE LA PERSPECTIVA DE LA IDENTIDAD DE MARCA (2001-2011)}

\begin{abstract}
Alberto Dafonte-Gómez ${ }^{\mathbf{1}}$ : Universidad de Vigo. España. albertodafonte@uvigo.es
\end{abstract}

\section{RESUMEN}

Si bien estamos habituados a considerar los formatos televisivos como fórmulas precisas y patrones estrictos que permiten reproducir un determinado programa en distintos mercados, lo cierto es que un formato, tras esa apariencia de rigidez que involuntariamente le conferimos -y que hasta cierto punto posee-, puede evolucionar a lo largo de los años para adaptarse a nuevas condiciones de mercado y tratar de garantizar su pervivencia, del mismo modo que las marcas pueden variar ligeramente a lo largo de su historia ciertos elementos de su identidad para adaptarse a los cambios en su entorno. El presente artículo pretende describir y analizar la evolución de los rasgos culturales -entendidos desde la perspectiva del marketing- que intervienen en la configuración de la identidad de marca del formato televisivo Operación Triunfo desde su primera emisión en España, en 2001, hasta la edición de 2011.

PALABRAS CLAVE: Televisión - Formatos - Branding - Marca

\section{EVOLUTION OF THE CULTURAL ASPECTS OF THE TELEVISION FORMAT "OPERACIÓN TRIUNFO" IN SPAIN FROM THE PERSPECTIVE OF BRAND IDENTITY (2001-2011)}

\footnotetext{
ABSTRACT

${ }^{1}$ Autor Correspondiente:

Alberto Dafonte-Gómez: Universidad de Vigo. Pontevedra. España.

Correo: albertodafonte@uvigo.es
}

Although we usually consider the television formats as precise formulas and strict patterns that allow to reproduce a program in different markets, the true is that a 
format, after this appearance of inflexibility that unintentionally confer him -and that to some extent possesses-, can evolve along the years to adapt to new conditions of market and treat to guarantee his survival, of the same way that brands can vary slightly along his history some elements of his identity to adapt to the changes in the environment. The present article pretends to describe and analyse the evolution of the cultural appeals -understood from the perspective of the marketing- that take part in the configuration of the brand identity of the television format Operación Triunfo from his first broadcast in Spain, in 2001, until the edition of 2011.

KEY WORDS: Television - TV Formats - branding - brand

\section{INTRODUCCIÓN}

Si aplicamos al terreno de los productos televisivos el concepto de identidad de marca desarrollado extensamente por la tradición investigadora del marketing a lo largo de los años, podremos observar que, si bien es necesario adaptarla a las especificidades del ámbito audiovisual, ofrece explicaciones complementarias a los procesos de producción de formatos televisivos descritos en las monografías sobre el tema.

La teoría del marketing distingue desde una etapa muy temprana en su desarrollo entre imagen e identidad como elementos clave en el desarrollo de una marca. Una de las referencias clásicas sobre la distinción entre ambos términos es la aportada por Margulies en un artículo publicado en 1977 en la Hardvard Bussines Review bajo el título "Make the most of your corporate identity". Según el planteamiento de Margulies la identidad se refiere a las decisiones propias que la empresa puede tomar con respecto a sus públicos, mientras que la imagen es el resultado de la percepción que esos públicos tienen de la empresa. La identidad se situará, por lo tanto, en el lado del emisor dentro del proceso comunicativo, mientras que la imagen lo hará en el lado del receptor.

Así pues, nuestro interés se centrará en las posibilidades que ofrecen los elementos culturales que conforman la identidad de marca para aportar una explicación alternativa a procesos y decisiones que afectan a la producción de los formatos televisivos, tomando como ejemplo el caso de Operación Triunfo en España.

\subsection{Aproximación a los elementos culturales de la identidad de marca}

Si revisamos algunos de los principales modelos de creación de identidad de marca (Kapferer, 1992/2008; Aaker, 1996 y Semprini, 1995) podemos identificar una serie de elementos que, tanto por su reiteración, como por la importancia que los distintos autores le confieren dentro de sus respectivas propuestas, se presentan como especialmente relevantes. 
Dentro de estos elementos podemos distinguir claramente dos grandes grupos que, según la nomenclatura de Sanz de la Tajada para la identidad corporativa ${ }^{2}$, podríamos denominar rasgos físicos y rasgos culturales de la identidad:

Los rasgos físicos incorporan elementos icónico-visuales como signo de identidad, válidos para la identificación de la empresa desde su entorno. Desde esta perspectiva, los elementos básicos de la identidad física de la empresa incluyen una forma simbólica -la marca- y una forma verbal -el logotipo-.

Los rasgos culturales, por su parte, incorporan los elementos profundos de la propia esencia de creencias y valores de la empresa; es decir, los rasgos de tipo conceptual y comportamental de la organización. (Sanz Tajada, 1994, p. 41)

Si bien sobre los elementos visuales de la identidad de marca -como el nombre, el símbolo o el logotipo- existe una notable coincidencia entre los distintos autores, sobre los elementos más ideológicos en la construcción de la marca existe una menor coincidencia, quizá precisamente por su cualidad de intangibles y por la dificultad que plantea su identificación inequívoca bajo un nombre concreto.

Por ejemplo, si revisamos el modelo planteado por Semprini (1995), comprobaremos que algunos de los elementos de creación de identidad de marca enunciados por el autor que tienen que ver con los objetivos, con el conocimiento de los consumidores y con el contexto sociocultural no figuran en ninguno de los otros modelos clásicos; sin embargo es obvio que en la creación de cualquier empresa hoy en día se tienen muy en cuenta las demandas -latentes o manifiestas- del mercado, para detectar las oportunidades de negocio, y también la influencia del contexto sociocultural en cuanto a valores y actitudes que la empresa debe respetar y seguir; del mismo modo, este conocimiento de públicos, mercados y entorno, así como los objetivos fijados, influirá en la construcción de la identidad de marca, pero no necesariamente bajo la consideración de elementos aislados, sino como componentes transversales que influirán en todas y cada una de las decisiones en torno a la identidad.

Con un mayor índice de aceptación y coincidencia entre los autores consultados hemos visto una serie de elementos que, aunque dispersos, tienen que ver con el concepto, la cultura y la filosofía de la marca, ligada en muchas ocasiones a la identidad del fundador $\mathrm{o}$ al país de origen.

Para Aaker (1996/2002) la mayor parte de los elementos internos que influyen en la creación de la identidad de marca se agrupan bajo dos perspectivas que generan una serie de asociaciones: la marca como organización y la marca como persona.

\footnotetext{
${ }^{2}$ A pesar de que consideramos que los elementos visuales que conforman la identidad de marca van mucho más allá del símbolo y el logotipo que menciona el autor, los conceptos generales propuestos por Sanz de la Tajada nos parecen muy útiles. Por lo demás, la transferencia de modelos entre identidad corporativa e identidad de marca resulta sencilla, siempre que tengamos en cuenta que, aunque similares, son cosas distintas.
} 
Las asociaciones organizativas contribuyen a una percepción positiva de la marca en la medida en la que la empresa matriz se haya ganado una reputación o se haya posicionado en el mercado como líder en atributos concretos. Las asociaciones organizativas aportan a la marca beneficios emocionales y de autoexpresión vinculando las impresiones del público sobre la empresa con cada una de las nuevas marcas que genera o con la construcción de la marca principal a lo largo del tiempo.

Para generar ese tipo de asociaciones es imprescindible que la identidad corporativa entendida como un concepto mucho más amplio que la simple identificación gráficaesté definida, previamente o de un modo simultáneo a la nueva marca, en términos de cultura empresarial, valores y concepto de marca. Sin duda todas las manifestaciones a las que dan lugar estas identidades, contribuyen a forjar en la mente de los consumidores una imagen determinada de la empresa que puede transferirse, para bien o para mal, a todas las marcas que agrupe.

Sobre la cultura y filosofía empresarial nos habla también Semprini (1995, p. 66), que incide en la importancia de la identificación clara por parte de la empresa de sus valores culturales -tanto los explícitos como los implícitos- para lograr configurar una identidad de marca "clara" y "coherente".

Por otra parte, también podemos hablar de las marcas atribuyéndoles características humanas que formarán parte de la identidad cultural de la empresa. Este planteamiento ha sido ampliamente desarrollado por Aaker bajo la premisa de que "el mismo vocabulario utilizado para describir a una persona se puede usar para describir la personalidad de la marca" (Aaker, 1996/2002, p. 152), por lo que podríamos caracterizarla mediante la atribución de sexo, edad, raza, posición social, carácter 0 comportamiento para posicionarla como honesta, sincera, joven, amigable, seria o excitante. En la medida en la que la personalidad de marca, que es un concepto clave en el planteamiento de Aaker y que también forma parte del prisma de identidad de Kapferer, puede facilitar la comprensión de ciertas percepciones de los consumidores sobre la marca, podrá también usarse la previsión de esas posibles percepciones como elemento orientador de la construcción de la identidad de la marca.

Otro de los elementos más relevantes de la identidad cultural de la marca, señalado por Kapferer (1992/2008) y ampliado posteriormente por Cerviño (2002), es el origen geográfico de la empresa y la decisión de usar o no ese elemento como baza en la construcción de la identidad de la marca. Normalmente esta decisión depende, en gran medida, de la existencia de asociaciones positivas entre la categoría de producto y el país de origen, motivadas por la tradición en su fabricación, la calidad percibida y la imagen de marca-país. En este sentido es sencillo ver las asociaciones que se establecen en productos como el ron cubano, los automóviles alemanes o las series estadounidenses y que, por sí mismas, ya pueden aportar un valor añadido a una marca comercial. Del mismo modo, otras marcas preferirán borrar el rastro a países de origen que no cuenten con una imagen positiva en la categoría de producto o que presenten menores beneficios que la adopción de una imagen globalizada. 
Todos estos elementos descritos en distintos términos por los diversos autores consultados no son más que las múltiples facetas del núcleo de identidad de la marca, que es el resultado de un proceso interno de toma de decisiones en cuanto a los aspectos culturales e ideológicos que guiarán todos los elementos visibles de la misma. Dentro de este núcleo se establecerán valores y asociaciones que sólo podrán transmitirse a los distintos públicos a través de acciones concretas de comunicación coherentes con esta esencia.

Pero, en el caso de los formatos televisivos ¿En qué se traduce este proceso de configuración del núcleo cultural de la identidad de la marca?

\section{METODOLOGÍA}

En la presente investigación se exponen un conjunto de resultados con el objetivo de describir y analizar la evolución de los rasgos culturales -entendidos desde la perspectiva del marketing- que intervienen en la configuración de la identidad de marca del formato televisivo Operación Triunfo desde su primera emisión en España, en 2001, hasta la edición de 2011

Esta investigación ha empleado como método teórico del conocimiento el método analítico sintético, concretamente para el análisis de las fuentes especializadas de información en el área disciplinar de los audiovisuales.

La caracterización y descripción de los elementos del objeto de investigación fue realizada mediante el método lógico-abstracto, en este caso para analizar puntualmente y de manera independiente las cualidades esenciales del objeto de investigación

\section{ANÁLISIS Y DISCUSIÓN}

\subsection{Principales condicionantes en la construcción de la identidad de marca: origen de la marca y destinatarios.}

Como ya hemos apuntado, la definición de una serie de valores y de una personalidad concreta para la marca es un elemento central en la creación de la identidad.

En este sentido, es necesario señalar dos condicionantes clave en la definición de los rasgos culturales de la marca: por una parte su origen y por otra sus destinatarios.

El origen de la marca suele ser una empresa o institución que se lanza a sí misma, a un producto o a una gama de productos, a un mercado. Por lo tanto ambos elementos estarán presentes e influirán de diversas maneras en la definición de la identidad de marca: desde la perspectiva del origen, en la medida en que recibe una herencia de los aspectos culturales de la identidad empresarial previa, y desde la perspectiva del destinatario, en la medida en que debe orientarse a satisfacer a un mercado y adaptarse a los condicionantes culturales de cada uno.

De las influencias de la identidad corporativa en la identidad de las distintas marcas 
que puedan surgir de una misma empresa nos hablaba Aaker (1996/2002) al tratar la marca como organización, lo que nos lleva a señalar la necesidad de tener en cuenta las transferencias de significado que se pueden establecer entre la empresa y las marcas de producto en todos los niveles tratados por otros autores: cultura empresarial, filosofía, raíces geográficas e históricas o concepto de marca. Todos estos elementos de la identidad cultural (y cualquier otro que eventualmente pueda tomarse en consideración) deben mantener una coherencia más o menos intensa con los atributos de la identidad de la empresa en función de la fortaleza del vínculo deseado entre empresa y marca ${ }^{3}$.

Un claro ejemplo de empresa que maneja una gran cantidad de marcas distintas en sectores tan dispares como la nutrición, la higiene personal y los productos de limpieza es la multinacional Unilever ${ }^{4}$. A pesar de no haber usado una estrategia de marca corporativa y haber optado por marcas diferenciadas en cada una de sus categorías de productos, Unilever pone un especial énfasis en conectar todas esas marcas bajo una clara definición de su misión corporativa:

Vitality es una palabra universal, con un significado similar en todas las lenguas, siempre relacionado con salud, energía, vigor, actividad, felicidad, sonrisa, etc.

Por este motivo nuestra misión puede resumirse en este concepto Vitalidad.

\footnotetext{
${ }^{3}$ Es necesario aclarar este matiz, puesto que, aunque habitualmente existen fuertes vinculaciones y trasferencias de significado entre las empresas y sus marcas -aprovechando la reputación construida para servir como garantía de calidad, por ejemplo- existen otros casos en los que algunas empresas que han desarrollado ampliaciones de línea de producto o extensiones de marca prefieren crear identidades específicas para sus marcas por distintos motivos.

Como ejemplos de empresas que disfrazaron el origen de sus marcas podemos citar el de Nissan, que desde los 40's hasta los 80's usó la marca Datsun para que no se vinculasen directamente sus vehículos ni con la empresa matriz ni, sobre todo, con su país de origen para introducirse en el mercado estadounidense; o Matsushita, que produce y comercializa aparatos de electrónica de consumo bajo las marcas más occidentalizadas de JVC y Panasonic. Existen también casos en los que una marca consolidada y con una fuerte identidad apuesta por una ampliación en su línea de productos que no se corresponde con su tradición y necesita desvincularse en cierta medida de sus nuevas creaciones. En estos casos y para minimizar trasferencias de significado que se suponen negativas -en ambas direcciones- se crean también nuevas marcas. Pueden ser los casos de Mercedes que creó una nueva marca -Smart- para lanzar al mercado vehículos de reducido tamaño y atrevido diseño, claramente alejados de la identidad tradicional de la firma alemana pero bajo las mismas premisas de calidad y precio elevado dentro de su gama; o de Lexus la marca creada por Toyota para sus vehículos de gama alta que pretende marcar una distancia sobre los utilitarios japoneses y adentrarse en la parcela de los vehículos de gama alta como BMW, Audi o Mercedes.

Dentro también del mercado del automóvil podemos encontrar ejemplos en sentido contrario, en los que una empresa decide apoyar con parte de su prestigio el lanzamiento o revitalización de una marca que, al mismo tiempo, mantiene una cierta distancia con la marca matriz al no producirse una identificación total, como en el caso del visible acompañamiento del grupo Renault a la expansión de la marca Dacia. Otro caso puede ser el de la multinacional de nutrición, higiene y cuidado personal Unilever que mantiene marcas diferenciadas para cada uno de sus productos asociadas de una manera discreta pero visible a la marca matriz.

${ }^{4}$ Unilever produce 400 marcas en 14 categorías de productos distintas, entre ellas algunas tan famosas como Rexona, Timotei, Skip, Signal, Tulipán, Lipton, Calvé, Pond's, Knorr, Ben \& Jerry's o Dove.
} 
Nuestra definición de la Vitalidad abarca un abanico de necesidades, desde un estilo de vida sana hasta gustarse a uno mismo, y disfrutar de más tiempo para compartir con los amigos y la familia.

[...] Vitalidad conecta los productos de Unilever con estos deseos universales de los consumidores. Nuestro portafolio de marcas aporta beneficios en materia de nutrición, higiene, salud y belleza, lo que nos concede una ventaja única para añadir vitalidad en todos los aspectos de la vida: dentro y fuera de nosotros, en casa y en el día a día.

En el área de alimentación estamos llevando a cabo nuestra misión a través de marcas y productos que proporcionan a nuestros consumidores los beneficios que aporta una buena nutrición para su salud, y ayudándoles a que disfruten del sabor y el placer de una adecuada alimentación.

En el área del cuidado personal y del hogar, se rompen estereotipos y se promueve los valores de la Vitalidad acercando nuestras marcas a la realidad de la vida a través nuestras campañas Ensuciarse es bueno, de Skip y Mujeres reales, de Dove. (Nuestra misión, 2010)

No se trata, por lo tanto, de mantener una identidad de marca monolítica aplicable a cada una de las categorías de producto en las que trabaje una empresa, sino de establecer aquellos elementos centrales de la identidad conceptual de la empresa que deben formar parte de la identidad de las nuevas marcas y sumarse a aquellos elementos propios y diferenciadores de cada una de ellas.

Por otra parte, la identidad de marca también estará influenciada en cierta medida por los valores y características de los consumidores a los que se dirige.

Al analizar el modelo de identidad de marca de Semprini (1995) y compararlo con otros, observábamos un especial énfasis en el estudio previo de los públicos y del entorno como elemento de la enciclopedia de producción (según la terminología del autor); al mismo tiempo señalábamos que, aunque en otros modelos se omita este concepto, entendemos que se trata de algo implícito en los procesos de creación empresarial puesto que todo producto o servicio debe responder 0 despertar necesidades del mercado al que se orienta y para ello es imprescindible conocerlo previamente.

Este condicionante, derivado de los valores culturales del mercado, afecta incluso a los valores transferidos de la identidad empresarial a los que ya hicimos mención, puesto que tanto los rasgos conceptuales de la identidad de marca, como los aspectos culturales de la identidad de la empresa deben corresponderse con los valores sociales del mercado al que se dirigen. No se puede concebir que una marca pueda adoptar como propios de su identidad valores que sean rechazados por la sociedad con la que debe relacionarse 0 , de un modo más concreto, por sus consumidores potenciales. 
Por este motivo la detección de las tendencias de mercado es vital para crear y mantener una identidad de marca adecuada y coherente con la evolución que puede producirse en sus consumidores.

A lo largo del tiempo han sido muchas las marcas que han realizado adaptaciones de su identidad y de sus manifestaciones según los cambios en la mentalidad y valores de sus mercados potenciales: eslóganes como "es cosa de hombres" de Soberano son impensables hoy en día, Coca Cola pasó de vender un tónico medicinal a ofrecer felicidad $y$, si volvemos nuestra vista hacia el sector automovilístico, veremos que, en los últimos tiempos, son muchos los fabricantes que intentan vincular la eficiencia energética y la preocupación por el medio ambiente a su identidad de marca.

La identidad de marca estará condicionada de una manera directa o indirecta por los valores sociales de cada época y por su evolución -o por los valores concretos del nicho de mercado al que se dirija- en la misma medida en que recibe las influencias identitarias de su empresa matriz. A nuestro juicio, la necesidad de contar con el mercado no implica una pérdida de la capacidad de definición de la identidad de marca por parte de la empresa puesto que la orientación al consumidor es una necesidad consustancial a cualquier negocio.

Esta doble vía de influencia afecta, como decíamos, a la definición de todos los rasgos culturales relacionados con la filosofía y la personalidad dentro de la identidad de marca, hasta concretarse en una propuesta a caballo entre lo tangible y lo intangible que es el concepto de marca: la promesa de beneficio que la marca realiza al mercado, basada en sus rasgos conceptuales, y con la mirada puesta en el diseño del producto.

Un caso que puede ejemplificar lo que estamos argumentando es el nacimiento de Cuatro, el canal de televisión en abierto de Sogecable que comenzó sus emisiones el 7 de noviembre de 2005, y que en su dossier de presentación se definía en los siguientes términos:

Una nueva televisión es posible. Una televisión entretenida, innovadora, divertida, actual, positiva, cómplice, interesante y joven.

¿Algo nuevo? Pues sí. Una nueva forma de construir una cadena que esperamos que se convierta en una nueva forma de mirar a la pantalla. Cuatro quiere gustar a mucha gente a la que le gusta la televisión pero que no se identifica con ninguna cadena.

Cuatro verá la luz con una gran experiencia a sus espaldas: quince años como principal referencia de la televisión de pago en España avalan al equipo de Sogecable para crear un canal diferente. Cuatro aportará una nueva oportunidad a la sociedad española para estar informada. Con rigor, con profesionalidad, con cercanía, con experiencia. (Cuatro, 2005). 
En esta simple definición dirigida fundamentalmente a los medios de comunicación, encontramos una alusión muy sencilla y directa a ciertos rasgos conceptuales de personalidad que parecen emanar de una definición de la identidad de marca más compleja ("una televisión entretenida, innovadora, divertida, actual, positiva, cómplice, interesante y joven"), pero también alusiones a las influencias en la configuración de esa identidad provenientes de los orígenes empresariales de la marca (a través de las alusiones a la experiencia de Canalt, que remiten a su vez al aura de calidad que acompañaba a la cadena de pago) y del público al que se dirige ("Cuatro quiere gustar a mucha gente a la que le gusta la televisión pero que no se identifica con ninguna cadena"). Sobre estas ideas propias de la identidad se construye el beneficio que la marca ofrece al mercado y su valor principal de cara a los consumidores, conformando así un concepto de marca, basado en una serie de atributos de la identidad conceptual, que debe traducirse en una aplicación coherente con los valores definidos al resto de elementos que conforman la identidad de marca.

\subsection{Rasgos culturales de la identidad de marca en Operación}

\subsubsection{Triunfo: descripción general del formato}

Para poder comprender la dimensión cultural de la identidad de marca del formato Operación Triunfo y su evolución entre la primera edición y la última, resulta imprescindible emprender una descripción -sintética en la medida de lo posible- del formato a través de los principales datos de cada una de las ediciones.

Una de las mejores fuentes de información para una aproximación rápida a lo que es Operación Triunfo es la propia web de los creadores del formato:

Es el formato de gran espectáculo creado por Gestmusic Endemol que con su mezcla de concurso y reality ha revolucionado los programas de entretenimiento musical y ha cautivado la audiencia a nivel mundial. En cada edición 16 jóvenes, después de superar un casting multitudinario, tienen la oportunidad de ingresar en la Academia de Operación Triunfo donde durante cuatro meses recibirán formación intensiva para convertirse en cantantes profesionales. Los concursantes cada semana deben demostrar sus actitudes, su evolución y ganarse el afecto del público en una gran gala musical en directo. (Operación Triunfo, 2010)

Efectivamente, tal y como señala la propia productora del formato -Gestmusic-, se trata de un producto que combina elementos de concurso, elementos del género musical y elementos de los reality-shows tal y como los concebimos después de Gran Hermano. Es interesante señalar, como punto de partida en la concepción de Operación Triunfo, la comparación con un referente inmediato, producido además por la matriz de Gestmusic -la holandesa Endemol- y estrenado con abrumador éxito en España tan sólo un año antes: Gran Hermano. Según recoge el Anuario de la televisión 2001: 
El interés y la expectación que genera Gran Hermano entre la audiencia española se traduce en cifras millonarias de espectadores, poco alcanzadas hasta el momento por otros espacios de televisión. El docu-show de Telecinco reúne una media de 8.286 .000 personas (en sus entregas de los miércoles y la final del viernes 21 de julio -presentadas por Mercedes Milá-), con lo que se convierte en el programa más visto de la temporada 1999/2000 y en el segundo con más audiencia desde 1993/1994, por detrás de la tanda de capítulos de Médico de Familia correspondiente a la campaña 1997/1998 (8.555.000 espectadores). (GECA, 2001, p. 228)

El increíble éxito de audiencia de Gran Hermano en su primera edición provocó que los rivales de Telecinco buscasen desesperadamente y con escaso éxito un killer format capaz de competir con el producto de Endemol; así fueron estrenándose formatos como El Bus, Estudio de actores o Confianza ciega, que nunca llegaron a las cotas de éxito del primero.

En este contexto de gran auge de los formatos de reality game show surge Operación Triunfo.

El formato Operación Triunfo es una creación de Toni Cruz y Josep María Mainat vinculados a través de su productora - Gestmusic- al grupo Endemol, productora a su vez de Gran Hermano. Según Cebrián Herreros (2003, p. 24) es posible que esta circunstancia orientase en cierta medida la idea inicial del nuevo formato, pero tampoco debemos olvidar que durante esos primeros años muchas otras productoras intentaron encontrar el killer format capaz de superar al referente manteniendo, en esencia, una serie de elementos esenciales que Sampedro enuncia como característicos de la McTele y que se dan, a grandes rasgos, en Operación Triunfo:

Los programas tipo Gran Hermano (McTele, de aquí en adelante) han sido calificados de "telerrealidad", "docu-games" o "socio-games". La televisión más comercial pretende retratar documentalmente y en tiempo real a gentes "normales" que aceptan encerrarse en ciertos lugares. Bajo el escrutinio de la audiencia, se someten a pruebas espectaculares, competiciones físicas y psicológicas, que dramatizan en clave emocional la vida cotidiana. La eliminación progresiva de los concursantes, entre sí y con los votos del público, aporta tensión e involucra a los televidentes. (Sampedro, 2002, p. 29)

Por otra parte tampoco debemos obviar la existencia previa de un talent show que revolucionó el mercado de los formatos musicales desde Nueva Zelanda en 1999 (a pesar de que no llegaría a España hasta 2002, estrenándose después de Operación Triunfo): Popstars, un concurso de cantantes creado por Jonathan Dowling que, si bien nació como un formato de aspecto documental sobre la creación de un grupo musical, pronto reveló que la fase de casting y selección de los componentes era el auténtico foco de interés. El formato británico Pop Idol -estrenado sólo unos meses 
antes que Operación Triunfo (05/10/2001)- recogió la idea básica de Popstars y añadió dos elementos clave en su éxito internacional: la participación del público por vía telefónica para decidir los ganadores (algo presente ya en Gran Hermano) y la incorporación al jurado profesional del polémico productor Simon Cowell quien, a través de sus ácidas valoraciones de las actuaciones de los concursantes, se ganó pronto un gran protagonismo dentro del formato. Otro elemento diferenciador con respecto a Popstars era la búsqueda de solistas y no de miembros para formar un grupo musical.

En este sentido el formato británico guarda muchas similitudes con Operación Triunfo, aunque también notables diferencias, puesto que en el formato español tiene una gran importancia la "reclusión" de los participantes - al estilo de Gran Hermano- en una suerte de centro de alto rendimiento musical, bautizado como "la Academia", en el que reciben formación en las disciplinas necesarias para "triunfar" en el mundo de la música y que, desde el punto de vista televisivo, supone uno de los principales atractivos del formato y una de las diferencias más notorias con los precedentes que hemos citado, aproximando el formato, a su vez, a la estela de Gran Hermano.

En todo caso, el referente directo en el mercado español era sin duda Gran Hermano y el interés de TVE en el formato produjo que se intentasen limitar al máximo los parecidos que Operación Triunfo tuviese con el producto holandés (Castañares,2007, p. 105) sin renunciar a un cierto nivel de "vigilancia" ni a la mecánica de expulsiones de los concursantes sometidas al juicio de la audiencia. Cebrián Herreros (2003, p. 24) señala como clave en la imagen positiva de Operación Triunfo el "haber convertido un trabajo académico, la actividad de un centro de formación, en un espectáculo televisivo" que daba como resultado un formato de telerrealidad que intentaba alejarse de la etiqueta de telebasura granjeada por Gran Hermano y que una televisión pública no podía permitirse.

La atención del formato se centró en las galas en las que los participantes actuaban y competían y en su preparación dentro de "la Academia", focalizando la atención en su experiencia formativa y dejando un cierto margen de privacidad para sus asuntos "personales", aspecto este contemplado en el propio diseño de producción:

Había sin embargo una importante novedad [con respecto a Gran Hermano]: una zona libre de cámaras que incluye los dormitorios, los baños y alguna que otra sala privada. Durante el tiempo en que están en esos lugares no se emiten imágenes en directo. En sentido estricto, pues no hay emisión en directo las veinticuatro horas. Se pretendía así evitar entrar en los aspectos más personales e íntimos de los concursantes. En palabras de uno de los responsables del programa nada interesa "lo que hagan [los concursantes] (sic.) en el dormitorio o en la ducha". Estas reservas no afectarían sin embargo a otros momentos íntimos. (Castañares, 2007, p. 105).

Tal y como se desprende de estos "centros de atención" que hemos descrito, Operación Triunfo no es un único programa de televisión: en realidad existen varias manifestaciones del mismo formato - susceptibles de ampliarse, como ha sucedido en 
su evolución desde 2001 a 2009- que combinan además elementos de distintos géneros.

En la primera edición podíamos hablar de las galas semanales en TVE1, de los resúmenes diarios en TVE2 (también de las emisiones y reemisiones de estos espacios a través del Canal Internacional), de la emisión 24 horas en Canal Operación Triunfo (televisión de pago) y del espacio Operación Triunfo: la Academia emitido en ambas plataformas, en el late night después de las galas en el caso de TVE1-, amén de las extensiones que posteriormente se fueron añadiendo a medida que el programa se consolidaba como líder de audiencia, como la gala especial Disney o Triunfomanía - que seguía la primera gira de los participantes una vez finalizado el concurso-; también se realizaron seguimientos diarios en otros programas del canal como Así son las cosas y apariciones especiales de concursantes y profesores en otros espacios.

En la edición 2009 el formato ya estaba consolidado en Telecinco y esta estructura de distribución en las parrillas, había sido ya enriquecida con nuevas propuestas, de modo que los contenidos del formato constaban de la emisión de los casting previos, las galas semanales, El Chat de OT -emitido a continuación-, resúmenes diarios y debates insertados en El programa de Ana Rosa por las mañanas y en Sálvame por las tardes, la emisión en La Siete (Telecinco2) de las conexiones en directo de OT: la Academia en directo y de los resúmenes diarios de Operación Triunfo: la Academia y, además, las emisiones del Canal Operación Triunfo 24 horas en plataformas de pago.

A este gran conglomerado de emisiones televisivas habría que añadir también la evolución en ese periodo de tiempo de los contenidos ofrecidos a través de Internet.

Como ya hemos señalado, el formato se desarrolló en España en dos etapas: una primera en la que es TVE el operador principal que emite Operación Triunfo tras el rechazo de los canales privados y una segunda en la que el formato es adquirido por Telecinco.

TVE emitió las tres primeras ediciones del concurso, que se celebraron entre los años 2001 y 2004, mientras que Telecinco fue el operador que emitió el formato entre 2005 y 2011.

La primera edición de Operación Triunfo contó con una primera fase que se desarrolló entre el 22/10/2001 (con la emisión de la "Gala 0", que servía de presentación de los concursantes) hasta el 11/02/2002, fecha en la que se emitió la "Gala Final" en la que se proclamaron vencedores, por este orden, Rosa López, David Bisbal y David Bustamante.

Sin embargo, los buenos resultados de audiencia motivaron que el programa se estirase todo lo posible una vez finalizada la fase de concurso, de modo que se siguieron emitiendo en las semanas sucesivas nuevas galas especiales, la preparación de los tres ganadores de entre los cuales se seleccionaría al representante en Eurovisión, la puesta a punto de la gira de verano que realizarían 
todos juntos y el lanzamiento de sus respectivos discos, de cuyo seguimiento se ocuparía un nuevo programa derivado del formato: Triunfomanía.

Dejando de lado sus implicaciones comerciales en cuanto a ingresos publicitarios, por llamadas y mensajes SMS, por ventas discográficas, merchandising y conciertos y centrándonos meramente en su éxito televisivo podemos reproducir, a modo de balance de la primera temporada, las reflexiones de Pérez Ornia y Gómez Amigo:

Operación Triunfo tiene un inicio discreto: su primera emisión es presenciada por 2.368.000 espectadores, el 22,2\% de la audiencia. Sin embargo, poco a poco se suman nuevos espectadores. La eliminación semanal de un concursante, el énfasis en el trabajo y esfuerzo de los participantes y el hecho de que las relaciones personales pasen a un segundo plano son algunas de las claves del éxito de este formato. [...]

Las tres últimas emisiones de OT se encuentran entre las 10 más vistas de la temporada y la última (11 de febrero), en la que Rosa es proclamada vencedora, se convierte en la más vista de los últimos 10 años: 12.873 .000 espectadores $(68,0 \%$ de share) están pendientes del resultado de las votaciones telefónicas. Nada menos que 14.425 .000 espectadores (el $80 \%$ del total de personas que en ese momento están viendo la televisión en España) sintonizan TVE1 entre las 23:56 y las 0:26 horas y siguen la elección de Rosa, David Bisbal y David Bustamante como los tres vencedores. [...] (Pérez y Gómez, 2003, p. 33)

La segunda edición comenzó el 07/10/2002 -aunque TVE2 había ya emitido los casting previos- sin que mediase apenas tiempo desde el fin de las postrimerías de la primera y se cerró con la "Gala Final" el 27/01/2002, en la que, siguiendo el mismo patrón que en la primera edición, se seleccionaban tres ganadores que deberían después batirse para lograr llegar a Eurovisión en dos nuevas galas.

De nuevo el formato se alarga para acoger en "la Academia" a los concursantes que han ido quedando fuera y prepararlos para las giras de conciertos en vivo; se estrena un nuevo programa derivado del formato, Generación OT, que se centrará en el seguimiento de los concursantes de la primera y segunda edición en sus giras, lanzamientos discográficos y preparación para el festival de Eurovisión de un modo similar al Triunfomanía de la primera edición. También se emiten resúmenes semanales los domingos por la tarde que no alcanzan los resultados esperados. Al calor del formato surgen nuevos programas del canal público que se benefician del atractivo de Operación Triunfo, como el magacín matutino Por la mañana, conducido por Inés Ballester y con amplios contenidos dedicados al formato de Gestmusic.

El desgaste del formato provocado por la excesiva sobreexposición de la primera edición hace mella en la segunda y la audiencia, aunque sigue siendo notable, se resiente considerablemente ("Menos audiencia, menos ventas, menos actuaciones y menos cachet para los chicos de 'Operación Triunfo'", 2002). 
La tercera edición vino a confirmar el desgaste al que el formato se había visto sometido en TVE, con una presencia continua también en otros medios de comunicación, CD's con las canciones de cada gala (más los especiales, como el de canciones Disney) o las giras veraniegas. Las galas logran una media del $23,3 \%$ de share en TVE1 y se quedan en el puesto 24 del ranking de programas más vistos; los resúmenes de TVE2 sólo alcanzan un 6,1\% (GECA, 2005).

Durante su etapa en TVE el formato Operación Triunfo y su estrategia de emisiones no experimentaron grandes cambios. Se mantuvo la estructura inicial de galas semanales, resúmenes diarios en TVE2 y programación en el Canal Operación Triunfo. Hubo ligeras modificaciones en cuanto al número de seleccionados en los casting, el sistema de votaciones telefónico, algunos profesores con más o menos tirón mediático, pero no elementos que cambiasen sustancialmente el formato.

El paso de Operación Triunfo a Telecinco en 2005 supone varios cambios que, si bien no implican una alteración en los elementos fundamentales del concepto de formato, sí que producen modificaciones importantes en su identidad con respecto a su etapa en TVE que se consolidarán en ediciones sucesivas.

Los primeros cambios visibles con respecto a sus anteriores ediciones fueron las sustituciones de Nina como directora de "la Academia" por el productor musical Kike Santander y del presentador de las galas Carlos Lozano por Jesús Vázquez, amén de las incorporaciones de nuevos profesores.

La estructura general se mantuvo muy similar aunque, a diferencia de anteriores ediciones, arrancó en verano y el objetivo de representar a España en Eurovisión desapareció por motivos obvios.

Telecinco comenzó el 13/06/2005 a emitir diariamente en la franja de access prime time los casting que se habían celebrado durante el mes de mayo, recuperando las emisiones de los casting en el access prime de TVE2 que habían funcionado bien en la primera edición. La "Gala 0" se celebró el 30/06/2005 y la "Gala Final" tuvo lugar el $13 / 10 / 2005$. Durante el periodo de duración del concurso se sustituyó la emisión de los casting por Operación triunfo: la Academia en la misma franja. La mecánica de nominaciones y expulsiones sufrió cambios notables, pero no especialmente relevantes para nosotros teniendo en cuenta los objetivos de esta investigación.

A partir del 28/07/2005 el éxito creciente de la nueva edición de Operación Triunfo propició el inicio de emisiones de El Chat de Operación Triunfo, que, una vez terminada la gala correspondiente - de un modo similar a como se hizo en la primera edición del formato- mantenía elevados índices de audiencia en la franja de late night bajo la batuta del profesor de "la Academia" Àngel Llàcer. Los buenos resultados provocan también que a principios de agosto se inicien las emisiones del canal 24 horas de Operación Triunfo a través de Imagenio.

En la cuarta edición del formato Telecinco logró reflotarlo hasta el punto de situar sus 
galas por encima de la media de audiencia de la segunda edición, logrando un 37,8\% de share y el segundo puesto en el ranking de programas más vistos de la temporada ${ }^{5}$ por detrás de Aquí no hay quien viva y un gran resultado en la "Gala final" con 6.745 .000 de espectadores y un $41,6 \%$ de share.

Como es natural, el jurado de las galas también experimenta cambios en la nueva etapa, pero a diferencia de otras ediciones en las que el papel del jurado había incluso perdido relevancia frente al público, uno de sus miembros, Noemí Galera (directora de casting de OT y de otros formatos de Gestmusic), adquiere un protagonismo especial por sus comentarios cortantes y por su "enfrentamiento" con una de las concursantes.

Este perfil de miembro de jurado "duro" iría ganando protagonismo como elemento de identidad del formato en sucesivas ediciones a partir de la incorporación de Risto Mejide en la edición de 2006, representando un papel similar al que popularizó el productor musical Simon Cowell como jurado de Pop Idol y American Idol.

Podemos afirmar sin duda que el jurado Risto Mejide se convirtió en la estrella indiscutible de Operación Triunfo, desde su aparición en la quinta edición (2006) hasta su marcha en la séptima (2009) eclipsando con sus comentarios las actuaciones de los concursantes y desplazando, en buena medida, el centro de atención del formato -establecido en la primera edición en torno a una serie de valores positivos como el esfuerzo o el compañerismo- hacia la confrontación del popular miembro del jurado con los concursantes (Sánchez, 2006)

La quinta edición de Operación Triunfo comenzó el 08/10/2006 -recuperando su periodo de emisión habitual coincidente con el inicio de temporada- aunque previamente se había usado el material de los casting por toda España para nutrir de contenidos a programas de la cadena como El programa de Ana Rosa, A tu lado o Aquí hay tomate, además de emitirse de nuevo como espacio independiente. La última gala del concurso se celebró el 26/01/2007 y durante todo el desarrollo del concurso se emitieron los resúmenes diarios en el access prime time.

La sexta edición de Operación Triunfo fue la confirmación de que la polémica y los conflictos personales habían desplazado definitivamente el centro de atención del formato. La nueva edición de Operación Triunfo comenzó también con la emisión de los casting, bajo el título de La semana OT, en el access prime time entre el $01 / 04 / 2008$ y el 08/04/2008, fecha de celebración de la primera gala. La gala final se celebró el 22/07/2008.

Sin duda existió una mejora notable en cuanto a vías de difusión y explotación del formato, con una apuesta decidida por el "segundo canal" de Telecinco y por las posibilidades de la web en lo relativo a la gestión de "comunidad de marca" a través

\footnotetext{
${ }^{5}$ Conviene aclarar que el dato del $37,8 \%$ se corresponde con las siete emisiones de galas que se celebraron dentro de la temporada y que se convierte en un $37,4 \%$ si consideramos el conjunto de las galas.
} 
del incremento de información audiovisual disponible y de posibilidades de comunicación e interacción entre fans y también entre fans y concursantes. Por otra parte Telecinco 2 se convirtió prácticamente en un canal temático de redifusión de contenidos emitidos previamente en Telecinco, pero también gozó de programas propios derivados del formato ("J esús Vázquez: 'Operación triunfo' es mi tesoro y como tal lo cuidaré", 2008).

Àngel Llàcer sustituyó a Kike Santander al frente de "la Academia" y volvió también a hacerse cargo del late night El Chat de OT aunque, sin duda, el elemento más destacado del formato en lo que a su identidad se refiere fue la potenciación del protagonismo de Risto Mejide con sus intervenciones cada vez más hirientes, sus reproches y enfrentamientos con los propios profesores de la academia particularmente con el director Àngel Llàcer- y su apoyo manifiesto a la concursante que a la postre resultó ganadora y con la que posteriormente colaboró en su primer disco. Una serie de hechos que sirvieron para escenificar un supuesto desencuentro entre el controvertido jurado y la productora - hasta el punto de abandonar el plató en la última gala- y que acapararon gran cantidad de las referencias realizadas sobre Operación Triunfo tanto en los programas de la cadena como en al conjunto de los medios de comunicación. La acidez de las valoraciones de Mejide consiguió incluso que el periódico británico The Times dedicase un artículo al jurado español que había superado a Simon Cowell en "grosería", al recriminar a una participante que abandonó el concurso debido a la muerte de su abuela (Catan, 2008).

La web del formato en Telecinco ${ }^{6}$, que en la edición anterior contaba con la categoría "Ristadas" para recoger las valoraciones más mordaces del miembro del jurado, amplió sus contenidos en torno a la figura de Risto Mejide con frases, vídeos, crónica rosa sobre su supuesta "relación especial" con la ganadora e incluso un juego de "recortables" en el que se podía "vestir" al jurado.

La expectación generada por los conflictos folletinescos provocados por Risto Mejide se tradujo en buenos resultados para la sexta edición de Operación Triunfo que logró un share medio del $26,4 \%$ con 3.812 .000 espectadores y que en la final logró 4.284 .000 de espectadores y el $34,4 \%$ de share, aunque en términos absolutos el número de espectadores se redujo considerablemente con respecto a la temporada anterior: era la primera edición de las emitidas por Telecinco en la que la audiencia media bajaba de los 4.000 .000 de espectadores, a pesar de lo cual seguía liderando en sus emisiones. El éxito televisivo de las galas se extiende también a El Chat de OT que alcanza muy buenos resultados.

La séptima edición se inició sin grandes cambios con respecto a la anterior aunque la fase de casting y selección previa recibe un tratamiento distinto. La media del concurso se situó en los 2.580 .000 y el $18,9 \%$ de share y algunas galas (13/05/2009 y $19 / 07 / 2009$ ) apenas superaron el 15\%. La Gala final se celebró el 13/07/2009 y obtuvo la peor audiencia de todas las ediciones del formato con 2.268.000 de

\footnotetext{
${ }^{6}$ www.telecinco.es/operaciontriunfo
} 
espectadores (unos 2.000 .000 menos que en la gala final de la edición anterior y con un $19,0 \%$ de share). Estas cifras convirtieron a Operación Triunfo 2009 en la edición con los niveles de audiencia más bajos en la historia del formato y motivaron que fuese también la edición más corta.

La estructura de programación apenas sufre cambios notables: se mantienen las galas semanales, el programa de chat posterior, los resúmenes y el seguimiento constante en otros programas del canal. Telecinco 2 se mantiene como una suerte de canal temático en abierto de Operación Triunfo con una parrilla totalmente dominada por el formato. Por su parte, la web continúa potenciando una participación más activa de la audiencia en el formato. Jesús Vázquez y Àngel Llàcer se mantienen como presentador y director de "la Academia" respectivamente, pero Risto está ausente en las primeras emisiones.

Los componentes del programa volvieron a ser las estrellas: por una parte se fichó a Ramoncín, cantante muy crítico con el formato desde sus inicios, hasta el punto de firmar en 2002 el manifiesto "Otro timo, no" en la que destacados miembros de la industria musical española criticaban al formato y su impacto en el mercado discográfico. Obviamente su participación en el programa generó cierta controversia y expectación pero lo cierto es que sus valoraciones no fueron especialmente destacadas; no así las de Risto Mejide que tras hacerse esperar se incorporó de nuevo con la fase de concurso ya iniciada y, más que nunca, centró toda la atención sobre su persona a través de conflictos constantes con concursantes, profesores, productora e incluso con el presentador, Jesús Vázquez, que, como buen conductor, siempre había ejercido de mediador y no de parte implicada. La crónica del encontronazo más destacado de la séptima edición del concurso - en la gala 10- nos da cuenta también de la repercusión en cuanto a niveles de audiencia de este tipo de práctica que se había venido perfeccionando a lo largo de la andadura de Operación Triunfo en Telecinco y que en la edición de 2009 alcanzó su máxima expresión:

A un lado, Jesús Vázquez: Lárgate ya, tío, déjame en paz. Vete a cagar. Al otro, Risto Mejide: "Christian Gálvez presenta muchísimo mejor que tú".

El público anima a su contrincante predilecto. No están sobre un 'ring', aunque lo parece. Ni siquiera protagonizan una tertulia televisiva de la más baja estofa. En realidad, los espectadores asisten al espectáculo de 'Operación Triunfo', un concurso que - en principio- busca y entrena voces privilegiadas para lanzarlas al estrellato.

Las jóvenes promesas se mantienen al margen, mudas, a la espera de que llegue su turno, mientras la bronca les come terreno. Pero el exabrupto puede con el gorgorito; sólo hay que detener la mirada en las curvas de audiencia para comprobarlo. El 'reality' producido por Gestmusic cosechó el martes una cuota media del 17,1\%; sin embargo, a las 00.15 horas, su 'share' se impulsó hasta el 33\% cuando el jurado Risto Mejide soltó a un participante, de nombre Ángel Capel: "En esa Academia tendría mucho miedo de dejar los orificios 
abiertos". A partir de esa 'perla', subió la tensión y, de manera directamente proporcional, el número de espectadores". (Fernández, 2009, p. 23)

En la siguiente gala se anunciaba la expulsión de Risto Mejide por su comentarios salidos de tono y poco después Telecinco le daba un programa propio en access prime time, G-20, hecho a la medida de su capacidad de crítica mordaz y deslenguada. Si bien el enfrentamiento y la expectación generada entre el público por lo que sucedería en la gala siguiente elevaron los niveles de audiencia en las galas 10 y 11, lo cierto es que a partir de ahí los resultados empeoraron notablemente, hasta el punto de que que Telecinco y Gestmusic decidiesen concluir el formato una semana antes de lo previsto.

La octava edición fue la confirmación de la debacle del formato y terminó, de manera repentina tras seis galas que habían logrado unos índices de audiencia muy inferiores a los esperados. Si bien en la primera (16/01/2011) alcanzaron el 17,7\% de share con 2.778.000 espectadores, en las sucesivas -a excepción de la gala final- no llegaron a rebasar el $14 \%$, llegando a caer hasta el $12 \%$. La última gala, que se anunció de forma subrepticia como "final" logró congregar 2.576 .000 espectadores $(14,7 \%)$ (“Telecinco cancela 'Operación triunfo 2011': gala final este domingo", 2011).

La intención de volver a los orígenes del formato se materializa, entre otras cosas, en la recuperación de Nina como directora de la Academia y en la definitiva ausencia de Risto Mejide como miembro del jurado. Además, dentro de los cambios producidos tras la "fusión" entre Cuatro y Telecinco, Pilar Rubio desplaza a Jesús Vázquez como presentador.

El planteamiento inicial es similar al de anteriores ediciones, con la salvedad de que no se explota el contenido de los castings y de que el formato no tiene tanta presencia en pantalla a través de resúmenes y programas derivados. También es notable, por novedosa, la apuesta decidida por la presencia del formato en redes sociales y particularmente en Twitter (Fernández, 2011, p. 34).

La breve crónica sobre la evolución del formato Operación Triunfo en España nos ha permitido observar notables diferencias en cada una de las dos grandes etapas que establecimos al inicio de esta sección. Así, si bien en la etapa en TVE podríamos decir que el formato se consideraba "blanco" frente a otro tipo de realities espectaculares por primar valores positivos como el esfuerzo y el compañerismo en vez del conflicto y las tensiones personales, la etapa del formato en Telecinco sólo conservó, en parte, esta identidad en la edición del año 2005; a partir de ese momento la orientación del formato va cambiando progresivamente hasta que, en 2009, se produce un segundo cambio de rumbo fallido que termina hundiendo definitivamente el formato, a la espera de una posible redefinición que permita retomarlo, quizás, en el futuro. 


\subsection{Rasgos culturales en Operación Triunfo.}

Cuando señalamos los rasgos culturales -en general- como elemento clave en la construcción de la identidad de marca distinguimos dos vertientes principales: por una parte aquellos aspectos de la identidad cultural de la marca "heredados" de la identidad de la empresa y, por otra, aquellos aspectos que se incorporan a la identidad derivados de las preferencias de la sociedad o del público objetivo.

En el caso de Operación Triunfo y de la influencia de la identidad corporativa en la identidad cultural del formato debemos atender a una doble vía de influencia: por una parte la productora que crea el formato y, por otra, el canal de televisión en el que se emite, influidos ambos por ciertas convenciones y gustos sociales.

La productora del formato es Gestmusic, productora española que ya en 2001 contaba con un amplio bagaje en formatos talent show y musicales como Lluvia de estrellas, Menudas estrellas, Tu gran día o La parodia nacional. Pero Gestmusic es también una de las productoras españolas pertenecientes al grupo Endemol -junto con otras como Zeppelin, Linze, Zenit o Diagonal Televisión- que revolucionó el panorama televisivo mundial con el fenómeno Gran Hermano.

Este origen empresarial condiciona sin duda la identidad de un formato que bebe directamente de las influencias de los talent shows y de los primeros formatos de telerrealidad al estilo Gran Hermano, fuentes ambas en las que tanto Gestmusic como Endemol tenían ya un cierto know-how y experiencia de desarrollo aplicable al nuevo formato. A este conocimiento, generado en el interior de ambas productoras a través de los procesos de desarrollo y producción de formatos anteriores más o menos relacionados con el concepto de Operación Triunfo, habría que añadir también la información aportada por antecedentes externos, como los ya citados PopStars o Pop Idol. De la combinación de distintos elementos presentes en estos antecesores, tanto propios como ajenos, podemos extraer algunos de los ingredientes que, combinados de una manera particular en Operación Triunfo, dan lugar a un formato único: un concurso de cantantes que busca solistas a los que ofrece como premio el lanzamiento de una carrera discográfica, el encierro y formación de los concursantes en un entorno de aprendizaje controlado y vigilado por las cámaras, la rentabilización de las votaciones telefónicas del público como vía de participación de la audiencia o la explotación del fenómeno musical generado a través de la venta de discos y de conciertos en directo. A todo esto habría que añadir -ya en la segunda etapa del formato- la presencia de un jurado mordaz que genera polémica con sus comentarios al ejercer de antagonista de los concursantes, produciendo empatía de los espectadores, bien hacia los concursantes, bien hacia el propio jurado.

Si bien todos estos elementos se corresponden más con la definición del producto que con aspectos culturales presentes en el formato, la conexión entre ambas categorías es directa, puesto que es lógico pensar que, del mismo modo que los géneros se van conformando por el progresivo asentamiento de elementos identificados como exitosos, un formato como Operación Triunfo tomará de otros formatos aquellos aspectos que demuestren conectar con la audiencia, sus valores y sus intereses. 
Habida cuenta de los referentes citados, podemos observar algunos rasgos de tipo cultural que forman parte de la identidad de Operación Triunfo en la medida en que han sido aceptados por los espectadores - a través de niveles de audiencia suficientes como para considerar el formato un éxito- y que giran en torno a dos polos principales que varían en dimensión a lo largo del periodo analizado: por una parte el talento, el esfuerzo y el aprendizaje; por otra, el conflicto, los sentimientos exacerbados y un cierto voyeurismo.

Durante su emisión en TVE Operación Triunfo se modeló según ciertos parámetros impuestos por el canal público para adaptar la identidad del formato a la identidad del canal y diferenciar el producto lo más posible de Gran Hermano y de las connotaciones negativas que lo acompañaban. Esta idea aparece recogida en la prensa con gran nitidez a través de las afirmaciones de Álvaro de la Riva, director de TVE en aquella época:

No queríamos hacer un Gran Hermano', explica De la Riva. Por eso, la cadena pública planteó varias condiciones para diferenciarlo y, entre ellas, impuso que el premio final no consistiera en dinero, sino en participar en el festival de Eurovisión. Además, en estas negociaciones surgió la idea de dar a los tres finalistas la oportunidad de grabar un disco. Y así se buscó una compañía discográfica. (Alcaide, 2001)

Como confirmación del posicionamiento de Operación Triunfo con respecto a Gran Hermano en el plano ideológico o moral podemos citar también las palabras de uno de los creadores, J osep María Mainat, quien afirmaba:

Cuando finalmente se estrenó Gran Hermano, comprendimos que ese formato representaba el concepto puro de un nuevo género y que, por tanto, era difícilmente mejorable. Pero todos los géneros, y más si se trata de géneros nuevos, permiten su ampliación y evolución. ¿Qué le puede faltar a Gran Hermano si es que le falta algo? Pues creímos que sería deseable que la convivencia tuviera un objetivo concreto y positivo. Por ello empezamos a desarrollar la idea de adaptar al nuevo género toda nuestra experiencia previa en programas musicales anteriores como Lluvia de estrellas, Menudas estrellas, Canciones de nuestra vida, Tu gran día, etcétera... formatos que se basaban en la búsqueda y desarrollo de nuevos talentos musicales. (Mainat, 2003, p. 65)

Cebrián Herreros señala, en esta línea, una serie de valores presentes, al menos, en las primeras ediciones del formato y que se concretan en los siguientes puntos:

a) Formación musical acompañada de otras enseñanzas- aprendizajes corporales, entonacionales y de relaciones sociales. Es un curso intensivo de educación en el esfuerzo, la convivencia, el sacrificio y la humildad 
b) Desarrollo de la personalidad y de la convivencia. [...]

c) Solidaridad y compañerismo que supera la rivalidad de un concurso.

d) Integración de los expulsados y de quienes permanecen en el concurso. Unos y otros en las partes de las Galas en grupo o en los números individuales correspondientes a los discos.

e) Trabajo en grupo. Todos los participantes se van rotando para interpretar individualmente, a dúo, trío o en conjunto. (Cebrián, 2003, p. 23)

Operación Triunfo fue un formato rechazado en primera instancia por los canales privados $y$, como vemos, la emisión a través de TVE supuso una serie de adaptaciones de la idea original a la identidad propia del canal, al menos en sus tres primeras ediciones. Sobre esta concordancia necesaria entre el posicionamiento del canal y el tipo de contenidos que emite habla Ramón Colóm, refiriéndose a la primera etapa de Operación Triunfo (antes -obviamente- de que el formato fuese adquirido por Telecinco):

TVE era la cadena propicia para este programa porque TVE es la cadena de los buenos sentimientos dirigida a la buena gente. No era posible, por ejemplo, en Telecinco, con la TV canalla de Sardá. Detrás de cada programación hay un modelo y un cierto modo de ver la vida que en TVE se traduce en Cuéntame, Operación Triunfo, Concha Velasco, films como Cadena perpetua, etc. (Ramón Colóm, 2002, p. 189)

Sin embargo, es precisamente a Telecinco a donde viaja el formato tras su paso por TVE y, como hemos relatado, Operación Triunfo sufre algunos cambios en la configuración del producto, reflejo de una redefinición de la identidad cultural del formato, que desplaza en cierta medida la atención del esfuerzo y aprendizaje del grupo, hacia los conflictos entre los concursantes, jurado y profesores. Una de las materializaciones más claras de esta redefinición es la incorporación de un jurado Risto Mejide- de perfil crítico y desconsiderado, a imagen y semejanza de Simon Cowell en Pop Idol, que se encargó de generar enfrentamientos con los concursantes y profesores de "la Academia" acaparando gran parte del protagonismo en todas sus intervenciones.

Si bien estos cambios otorgaron al formato un nuevo periodo de esplendor, lo cierto es que la última edición de Operación Triunfo con Risto Mejide sólo consiguió acercarse a niveles de audiencia de ediciones pasadas en momentos de máximo enfrentamiento, como el ya descrito entre el presentador Jesús Vázquez y el jurado, obteniendo unas cifras de audiencia media decepcionantes y provocando un gran desgaste en la imagen de prestigio que un día logró forjarse el formato entre amplios sectores sociales.

Posiblemente la mejor muestra de la deriva en la identidad original del formato durante sus cuatro últimas ediciones sea la pretensión de "volver a los orígenes" 
manifestada durante la presentación de Operación Triunfo 2010. Una de las expresiones más claras de esta pretensión es la reincorporación de Nina, la que había sido directora de "la Academia" en las tres primeras ediciones de Operación Triunfo, quien declaraba en la presentación:

La formación de los concursantes - para mí son únicamente alumnos- va a ser integral, basada en la filosofía que impera en cualquier escuela de interpretación 0 en los centros de alto rendimiento para deportistas. Una formación profesional que engloba además valores humanos y personales, con asignaturas específicas para formarles en estos aspectos. Será una especie de master artístico con el que pretendo volver a los orígenes de este formato. ("Nina vuelve a Operación Triunfo", 2010).

En este sentido se expresaba también Jesús Vázquez en el mismo evento ("Nina vuelve a Operación Triunfo", 2010): "Volveremos a recuperar la esencia de la Academia" o el propio Mainat (Aniorte, 2010): "[los responsables de 'OT' echan la vista atrás para que el concurso] 'vuelva a su espíritu original. Aquel en el que lo importante eran los futuros cantantes y no los que se dedicaban a juzgarlos'". Esta orientación tan insistente en las declaraciones de los principales responsables de Operación Triunfo hacía suponer que se produciría una redefinición de los elementos culturales de la identidad del formato que lo acercasen más a sus orígenes y a los valores (mediatizados) del esfuerzo, el aprendizaje y el compañerismo.

Sin embargo, el cambio de orientación en la identidad del formato concluye con la cancelación súbita del programa a las pocas semanas de iniciar su octava edición debido a los malos resultados de audiencia.

El cambio del presentador habitual del formato en Telecinco -Jesús Vázquez- por una más inexperta Pilar Rubio, la ausencia de Risto Mejide, los cambios improvisados en un jurado inicial que parecía no convencer, y un arranque del formato sin la fase de castings que durante la etapa en el canal de Mediaset se había convertido en práctica habitual son algunas de las diferencias con respecto a ediciones anteriores que pudieron influir en los datos negativos que Operación Triunfo comenzó a cosechar tras la emisión de la gala inicial. El gran cambio en la identidad que desde la productora se prometía en las ruedas de prensa previas no llegó a materializarse 0 , al menos, no del modo que cabía esperar a tenor de las declaraciones que reproducimos.

\section{CONCLUSIONES}

Las decisiones de la fase de desarrollo sobre los contenidos, la estructura, la mecánica de funcionamiento, el tono o los presentadores y colaboradores conforman un conjunto sinérgico que dotará al formato de unas características únicas y diferenciadoras frente a formatos similares y determinarán las posibilidades de negocio del mismo.

En un contexto en el que, cada vez más, las productoras audiovisuales luchan por 
crear formatos que puedan vender a nivel internacional y de los que se puedan derivar todo tipo de negocios paralelos que aumenten la rentabilidad del producto, parece lógico mirar hacia el proceso de desarrollo de los formatos televisivos con los ojos del marketing y, más concretamente, del branding para que todas las decisiones de tipo creativo estén orientadas por la lógica de la creación de marca.

Uno de los estadios iniciales de la creación de marca tiene que ver, como hemos visto, con la definición de los rasgos culturales de los que deben partir el resto de características de posicionamiento y, en el caso concreto de Operación Triunfo, hemos observado que esas bases culturales se alteraron con el paso del formato de un canal público como TVE a uno privado como Telecinco. Las especificidades de cada uno de los emisores y el contexto de cada una de estas etapas se traduce en una serie de cambios perceptibles en el desarrollo del formato, en su dinámica narrativa y en los focos de interés en cada momento: el esfuerzo, el aprendizaje y la superación en una primera etapa y el morbo, la confrontación y el conflicto en la segunda.

El negocio de la televisión está inmerso en un proceso de cambio motivado por las nuevas tecnologías y por las nuevas pautas de consumo que adoptan los usuarios gracias a ellas: fenómenos como el consumo a la carta y en diferentes pantallas, la televisión over-the-top y la influencia de las redes sociales en los hábitos de visionado y participación en los contenidos hacen que, cada vez más, las productoras y los canales de televisión deban esforzarse por crear marcas potentes en torno a los formatos televisivos que permitan una optimización de resultados en las distintas plataformas disponibles para ellos.

\section{REFERENCIAS}

Aaker, D. (1994). Gestión del valor de la marca. Capitalizar el valor de la marca. Madrid: Ediciones Díaz de Santos.

Aaker, D. (2002). Construir marcas poderosas.Madrid: Gestión.

Aaker, J. L. (1995). Conceptualizing and measuring brand personality: A brand personality scale.Standford University.

Alcaide, S. (2001, 23 de diciembre). Operación Triunfo, el espacio al que no le basta el éxito. El País. Consultado el 4 de Octubre del 2009, Disponible en:

www.elpais.com/visorpdf/?d date $=20011223$

Aniorte, C. (2010, 3 de junio). Nina regresa a «OT» para que el concurso recupere su espíritu original. $A B C$. Consultado el 10 de Junio del 2010, Disponible en:

www.abc.es/20100603/radio-television-radio-television/nina-regresa-para-concurso20100603.htm

Castañares, W. (2006). La televisión moralista. Valores y sentimientos en el discurso televisivo. Madrid: Fragua. 
Catan, T. (2008, 18 de abril). Spanish pop judge who is even ruder than Simon Cowell. The Times. Consultado el 10 de Abril del 2010, Disponible en:

\section{www.timesonline.co.uk/tol/news/world/europe/article3768201.ece}

Cebrián Herreros, M. (2003). Estrategia multimedia de la televisión en Operación Triunfo. Madrid: Ciencia 3.

Cerviño, J. (2002). Marcas internacionales. Cómo crearlas y gestionarlas. Madrid: Ediciones Pirámide.

Colóm, R. (2002). Las claves de 'Operación triunfo'. Fotogramas, 55 (1901), 189.

Cuatro (2005, 7 de Noviembre). Dossier presentación. Consultado el 7 de Noviembre del 2009, Disponible en el sitio web de Cuatro:www.cuatro.com

Fernández, E. (2009, 7 de julio). Dame una bronca y engancharé a la audiencia. El Mundo. Consultado el 06 de Marzo del 2010, Disponible en:

\section{www.elmundo.es/elmundo/2009/07/08/television/1247081685.html}

Fernández, L. (2011, 16 de febrero). Ser 'trending topic' no basta para salvar a Operación Triunfo. Consultado el 10 de Febrero del 2009, Disponible en:

http://blogs.lainformacion.com/twitter-blog/2011/02/16/ser-trending-topic-nobasta-para-salvar-a-operacion-triunfo/

El realismo televisivo (2001). En GECA (ed.). El Anuario de la televisión 2001 (pp. 22835). Madrid: GECA.

Formula TV. (2008). Consultado el 17 de Marzo del 2009, Disponible en: www.formulatv.com/1,20080328,7163,1.html

Kapferer, J. N. (2008). The new strategic brand management. Creating and sustaining brand equity long term. Londres: Kogan Page

Kapferer, J. N. \& Laurent, G. (1991). La sensibilidad a las marcas. En J. Kapferer \& J. Thoenig (Eds.), La marca. Motor de competitividad de las empresas y del crecimiento de la economía (pp. 39-68). Madrid: McGraw Hill.

Kapferer, J. N. y Thoenig, J. C. (1991). La marca. Motor de competitividad de las empresas y del crecimiento de la economía. Madrid: McGraw Hill.

Mainat, J. M. (2003). El triunfo de la telerrealidad. En GECA (Ed.), El Anuario de la televisión 2001 ( p. 65). Madrid: GECA.

Margulies, W. P. (1977). Make the most of your corporate identity. Hardvard Bussines Review, (julio-agosto): 66-72. 
Nina vuelve a Operación Triunfo. (2010). Consultado el 2 de Marzo, 2010, Disponible en:

www.vertele.com/noticias/27211/\%C2\%A1nina-vuelve-operacion-triunfo

Nuestra misión (2010). Consultado el 10 de Marzo, 2010, Disponible en: www.unilever.es/nuestrosvalores/misionvision/mision/default.asp

Operación Triunfo. (2010). Consultado el 20 de Mayo, 2010, Disponible en: www.gestmusic.es/fitxa.php?id=1\&m=3\&tp=10

Pérez Ornia, J. R. \& Gómez Amigo, S. (2003). La 'telerrealidad' se consolida como género hegemónico". En GECA (Ed.). El Anuario de la televisión 2003 (pp.10-59). Madrid: GECA.

Sampedro, V.r (2002).Telebasura: McTele y ETT. ZER, (13): 29-49.

Sánchez, G. (2006). Risto Mejide, el malo más famoso de la televisión. Informativos Telecinco. Consultado el 19 de Diciembre del 2006, Disponible en:

www.informativos.telecinco.es/risto mejide/operacion triunfo/jurado/dn 38116.htm

Sanz de la Tajada, L. A.I (1994). Integración de la identidad y la imagen de la empresa. Desarrollo conceptual y aplicación práctica. Madrid: ESIC.

Semprini, A. (1995). El Marketing de la marca: una aproximación semiótica. Barcelona: Paidós.

Telecinco cancela 'Operación triunfo 2011': gala final este domingo". (2011). Consultado el 17 de Febrero, 2011. Consultado el 19 de Diciembre del 2006, Disponible en:

www.formulatv.com/noticias/18398/telecinco-cancela-operacion-triunfogala-final

\section{Alberto Dafonte Gómez}

Doctor en Comunicación Audiovisual y Publicidad por la Universidad de Vigo con la tesis titulada Creación de identidad de marca en contenidos televisivos: aplicabilidad de modelos teóricos a los formatos de entretenimiento en televisión (2010). Es profesor a tiempo completo en la Facultad de Ciencias Sociales y de la Comunicación de la Universidad de Vigo desde 2005 e imparte en la actualidad Teoría y Práctica de la Comunicación Televisiva en el Grado en Publicidad y Relaciones Públicas. 